\title{
Societal views and animal welfare science: understanding why the modified cage may fail and other stories
}

\author{
D. M. Weary ${ }^{\dagger}$, B. A. Ventura and M. A. G. von Keyserlingk \\ Animal Welfare Program, Faculty of Land and Food Systems, University of British Columbia, 2357 Main Mall, Vancouver, BC V6T 1Z4, Canada
}

(Received 17 January 2015; Accepted 28 May 2015; First published online 24 July 2015)

\begin{abstract}
The innovations developed by scientists working on animal welfare are often not adopted in practice. In this paper, we argue that one important reason for this failure is that the solutions proposed do not adequately address the societal concerns that motivated the original research. Some solutions also fail because they do not adequately address perceived constraints within the industry. Using examples from our own recent work, we show how research methods from the social sciences can address both of these limitations. For example, those who persist in tail-docking cattle (despite an abundance of evidence showing that the practice has no benefits) often justify their position by citing concern for cow cleanliness. This result informs the nature of new extension efforts directed at farmers that continue to tail dock, suggesting that these efforts will be more effective if they focus on providing producers with methods (of proven efficacy) for keeping cows clean. Work on pain mitigation for dehorning shows that some participants reluctant to provide pain relief believe that the pain from this procedure is short lasting and has little impact on the calf. This result informs the direction of new biological research efforts to understand both the magnitude and duration of any suffering that result from this type of procedure. These, and other examples, illustrate how social science methodologies can document the shared and divergent values of different stakeholders (to ensure that proposed solutions align with mainstream values), beliefs regarding the available evidence (to help target new scientific research that meets the perceived gaps), and barriers in implementing changes (to ease adoption of ideas by addressing these barriers).
\end{abstract}

Keywords: public attitudes, animal well-being, producer engagement, science policy

\section{Implications}

Many of the innovations developed by animal welfare science have failed to see widespread adoption in practice. One reason for this failure may be that science-based 'solutions' fail to resonate with the values and concerns of other important stakeholders. Here we use examples from our past work with dairy cattle to argue that new scientific research should occur in tandem with social science research that provides a better understanding of the welfare concerns of the general public and perceived barriers of livestock producers.

\section{Introduction}

Here is a dirty secret. Careers have been frittered away, and with them millions of dollars in investment, on ideas of animal welfare scientists that have never gained traction in the real world. Consider, for example, the modified cage for laying hens. The modified cage is an elegant scientific solution, taking

\footnotetext{
${ }^{\dagger} \mathrm{E}$-mail: danweary@mail.ubc.ca
}

into account our best research on social group size, risks of feather pecking and cannibalism, the benefits of perches, dust bathing opportunities and a secluded nest site (see Lay et al., 2011; Mench et al., 2011). This research, combined with years of engineering and marketing efforts, to create another cage for laying hens. This happened without, it seems, any serious investment in finding out what the general public (and critics of existing cage systems for layers) wanted and what elements they would consider essential in housing systems for birds. Arguably this leaves us with a solution that appeals to a more narrow conception of welfare held by the scientists, but fails to resonate with the concerns of others who from the outset wanted cage-free systems and are thus generally less willing to support a production system based on cages, even if these are labelled 'enriched', 'modified', etc.

\footnotetext{
${ }^{1}$ We use the term 'public' here to mean those who hold no affiliation to livestock production. The public can still influence what happens on farms in their roles as consumer and citizen. The consumer's role is in a market context as a purchaser (or boycotter) of animal products, while the citizen participates in the social and political context by voting or exerting social pressure and contributes to a social consensus as part of civil society (see Aerts, 2013).
} 
Weary, Ventura and von Keyserlingk

As explained by Fraser (2008), animal welfare science is mandated to provide solutions to the problems brought to us by the society that funds our positions and the institutions in which we serve. However, our own values bias the work we do, including what we choose to measure and how we interpret the results. Consider a hypothetical researcher who sets out to study the welfare of laying hens kept in modified cages $v$. a well-designed free-range system. She might choose to measure pathogen exposure or risk of feather pecking, and on this basis conclude that welfare is superior in the modified cages. But this choice of measures (and many other choices including the specific conditions under which the different systems are studied) reflects her values as an individual. Other scientists might have made different but equally rational choices, for example, studying the hen's ability to fully stretch her wings, or aspects of foraging behaviour (both behaviours might be restricted in cages relative to cage-free systems). The problem is not that such biases occur; it is our blindness to these biases. This failing is arguably more problematic if the biases we bring to our work do not correspond with the values of the society that mandated our work in the first place. In the current example, people who buy eggs of course expect that animals will be kept healthy (Vanhonacker et al., 2010; Ingenbleek and Immink, 2011), but public concerns regarding how farm animals are reared also focus on long periods of close confinement and how this reduces opportunities for animals to live a more natural life (e.g. Boogaard et al., 2011; Vanhonacker et al., 2008).

This type of mismatch may be better avoided if efforts to describe and understand social concerns (e.g. Krystallis et al., 2009; Boogaard et al., 2011) are used to inform the direction of scientific work. In the current example, we suggest that if a sustained research effort to understand societal values around cage and non-cage rearing for laying hens had predated or at least accompanied the scientific work, research would have instead focused on the development of highwelfare non-caged systems that are more likely to see widespread adoption in practice.

Understanding the values and beliefs of farmers and other industry professionals (e.g. veterinarians) is equally critical. These individuals often serve as the 'gate keepers' in deciding if and how to implement innovations (Kauppinen et al., 2010; Driessen, 2012). Understanding the perspectives of farmers is now increasingly recognized as a critical component in resolving challenges in food animal production (Feola and Binder, 2010; Kaupinnen et al., 2010; Driessen, 2012; Hansson and Lagerkvist, 2014).

In this paper, we make the case that some solutions developed by animal welfare scientists fail to gain traction because (1) they do not adequately address the societal concerns that motivated the original research and (2) they do not adequately address the perceived constraints within the industry. We argue that scientists, policy makers and funders working on animal welfare must increasingly invest in social science research that addresses these limitations. We provide examples from our own research on dairy cattle to illustrate how social science methodologies can document the shared and divergent values of different stakeholders, the beliefs regarding the available evidence and the barriers in implementing changes. We argue that the results of these studies can help identify solutions that better align with mainstream values, help target new scientific research that meets the perceived gaps in knowledge, and help ease the adoption of innovations by specifically addressing perceived barriers.

\section{A short primer on theory and methods}

The Theory of Planned Behaviour (Fishbein and Ajzen, 1975; Ajzen and Madden, 1986) is one of the prevailing paradigms in social psychology and communication. This framework posits a causal chain of influence in which attitudes, influenced partially by one's beliefs and values, affect human behaviour.

According to the Theory of Planned Behaviour, one's intention to perform a particular behaviour is the most powerful predictor of that behaviour. Intention in turn is then influenced by both attitudes and subjective norms, where subjective norms involve how a person perceives social pressure from peers to perform or eschew the behaviour in question (Ajzen and Fishbein, 1980). An attitude is a disposition to respond favourably or unfavourably to an attitude object, which can be anything concrete or abstract that a person is able to hold in mind (definition adapted from Cross, 2005). For example, the general idea of a 'factory farm', the act of using analgesics for dehorning, or even the dairy cow herself can all be considered attitude objects towards which someone may hold positive or negative attitudes (N.B. 'view' and 'opinion' are often used as proxies for 'attitude').

Attitudes in turn are a partial function of the evaluation of the beliefs held about the attitude object along with the strengths of those beliefs. Apart from helping to predict behaviour, the study of attitudes also becomes useful because it can help reveal the values and beliefs that underlie them. Beliefs represent the composite of information someone holds about an attitude object and link the object with certain attributes (Fishbein and Ajzen, 1975). For example, the belief that 'dehorning is painful for the calf' links the psychological object 'dehorning' to the attribute 'is painful for the calf', and would likely contribute to forming a negative attitude to the practice. Beliefs are often evaluative in nature, such that they apply a value judgment.

Values root both belief and attitude formation (Bem, 1970; Seligman et al., 1996; Ajzen, 2001). Values can be thought of as 'desirable, trans-situational goals... that serve as guiding principles in people's lives...' (Seligman et al., 1996). Values form a foundational platform through which an individual views the world. This is why people's values about animal welfare are relatively impervious, regardless of the level of information that they might have about a specific practice (see Hansen et al., 2003). It also explains why educational efforts towards the goal of, say, heading off criticisms about husbandry practices in the livestock industries often fall short: they fail to address the deeply held values that people hold around animal care. 
A variety of methods have been applied to inquiries into stakeholder attitudes on farm animal welfare. Much of the work to date in North America has been based on quantitative surveys (e.g. Heleski et al., 2004, 2005 and 2006; Heleski and Zanella, 2006; Levine et al., 2005; Prickett et al., 2010). Survey studies have real benefits: they can be deployed on a broad scale and can be designed to capture representative samples that offer the opportunity to generalize to broader populations. But people's perceptions of farm animal welfare are complex; uncovering the basis of concerns likely requires a more in-depth approach than can be achieved by quantitative survey work alone. Indeed, 'social scientists tend to be sceptical about the notion that lay attitudes to distinct issues... can be studied in abstraction within a quantitative or statistical framework. In daily life, these issues rarely arise other than in an interconnected or merged way [...] experience is less likely to be distorted if it is studied discursively within a less rigid, more qualitative framework' ( Hansen et al., 2003, p. 117).

European researchers have pioneered work on qualitative approaches to understanding stakeholder values around animal welfare (e.g. Borgen and Skarstad, 2007; Kauppinen et al., 2010; Vanhonacker et al., 2010; Benard and de Cock Buning, 2013). Qualitative methods of inquiry can vary, but typically include interviews, focus groups and field research (ethnography). A common thread is the motivation to understand the meanings and experiences of these stakeholders, and to uncover the social and psychological phenomena behind the patterns described in quantitative approaches (Warren and Karner, 2010).

Qualitative research can involve either in-person or online interactions; both have their advantages. For example, online forms of inquiry provide an efficient and cost-effective way to reach large groups of people in a short period of time (Danielson, 2010), but lack the flexibility that would allow clarification or pursuit of a relevant thread of conversation. In-person approaches such as interview and focus group studies can be difficult to organize and expensive to deploy, but allow the researcher to probe for more information if a respondent is unclear. Focus groups also have the added benefit of eliciting dynamic conversation in a social context (Pivetti, 2007).

A mixed method approach will aid in capturing both the breadth and depth of the various psychological constructs that inform how people relate to the welfare of farm animals. Quantitative results help to contextualize qualitative findings, and qualitative results help to understand the reasons behind any quantitative differences observed. Qualitative methods such as interviews or focus groups can also be used to identify the range of relevant issues and used to design better-targeted quantitative studies (Brannen, 2005).

\section{Case studies of our work}

One approach that we have found useful is an interactive online platform, designed in concert with the University of British Columbia's Centre for Applied Ethics (Danielson,
2010). Our intent has been to foster informed discussion between farmers, critics, consumers and other stakeholders on controversial issues relating to dairy cow welfare. Our Cow Views website created online forums designed to mimic town hall meetings, in that people from anywhere could access the site, access some background material on the issue (to help ground people's comments with a minimum level of basic knowledge), and indicate whether they supported, opposed or were neutral to the practice in question. Participants were also asked to explain their position or to select reasons written by previous participants (providing a type of social context). This mixed approach allowed us to not only gauge levels of support (the quantitative aspect), but also the reasons behind it (the qualitative aspect).

Below we examine four case studies using this method. These examples illustrate how participant responses can identify contentious issues and approaches to resolving them. Our surveys were available on the Internet so anyone with Internet access could participate, but we encouraged participation of people in the North American dairy industry by publishing the link with brief articles in producer magazines (Progressive Dairyman and Ontario Farmer) that invited readers to participate. We also recruited dairy industry participants at conferences (e.g. the Western Canadian Dairy Seminar) and via e-mail (e.g. to members of the American Association of Bovine Practitioners). In addition, we recruited more demographically diverse participants using a commercially available recruitment tool (Amazon's crowd-sourcing service, Mechanical-Turk). Mechanical-Turk provides access to respondents known to be more diverse than standard Internet samples and college students (Casler et al., 2013). These recruitment methods were used to elicit a wide range of perspectives and were not intended to be statistically representative of any particular population. Indeed, our sample had more cattle industry participants than would be expected in a random sample; participants also tended to be younger (under 30 years old) and female.

\section{Tail docking}

Why do some dairy farmers continue to dock the tails of their cows? The procedure was once believed to reduce the risk of the zoonotic disease leptospirosis but this idea has long been debunked (Mackintosh et al., 1982). Others have suggested that the cows with docked tails are cleaner, and thus at lower risk of udder infection, but a series of studies have shown that there is no protective effect of docking on cleanliness or mastitis (Eicher et al., 2001; Tucker et al., 2001; Schreiner and Ruegg, 2002; Fulwider et al., 2008; Lombard et al., 2010). Why then would some dairy farmers continue to spend time and money to conduct a procedure that harms their cows (by removing their natural fly-swatter) and harms the reputation of their industry?

The answer can be found, at least in part, in the responses obtained from social science work (Barnett et al., 1999), including our own online engagement exercise on the question of tail docking (Weary et al., 2011). The reasons 
provided by participants in support of docking showed a strong concern for cow cleanliness and udder health, combined with a belief in the efficacy of docking in addressing these problems. For example, one participant argued that docking is beneficial because... 'on some farms it is an effective way to keep cows clean and prevent them from splashing manure everywhere'. Another argued that 'cattle in tie stalls and free stalls tend to have their tail lying in urine and manure, thus swishing urine and manure all over themselves and their stable mates. Now picture this, you have to go wash udders and attach milkers all while tails are swishing back and forth'.

Thus, one reason why some farmers continue to dock their cows (even in Canada where the practice is not allowed under the producers' own Code of Practice for the Care and Handling of Dairy Cattle, National Farm Animal Care Council, 2009; see also Lerner and Algers, 2013 for the related case of poor compliance within Europe concerning tail-docking for piglets) is that they place high value on health and hygiene and thus are highly motivated to do something that they believe might help. This motivation to address problems with cow cleanliness may explain why farms that dock dairy cows actually have dirtier cows (Lombard et al., 2010); these farmers may recognize that they have a problem with cow hygiene and use docking in a misguided attempt at improvement. Similarly, lying cubicles for cows are often configured with the aim of keeping the lying surface clean (e.g. by using an aggressive neck rail placement that prevents cows from standing in the stall; Bernardi et al., 2009), even though prolonged standing outside of the stall increases the risk of lameness (Bell et al., 2009).

One productive approach may be to focus education events for dairy farmers on effective methods for improving cow cleanliness. For example, one important cause of faecal soiling is that cows sometimes defecate onto the lying surface. The resulting soiling may be addressed in several ways, such as more frequent bedding management, including routine raking of the stall surface to ensure that this is clean and dry. Another way of keeping cows clean is to allow them improved opportunities to groom (e.g. by providing access to a mechanical brush; see DeVries et al., 2007). Grooming not only restores hygiene, it also provides cows the opportunity to engage in a valued natural behaviour. Farmers especially concerned about the role of the tail as a source of faecal soiling may wish to consider switch trimming as a less invasive alternative. This combined approach targets the concern and provides positive alternatives that address farmers' values around cleanliness without creating the welfare issues associated with tail docking.

Research is also required to better understand the effects of cow housing and management on cow cleanliness. The natural behaviour of cattle is to defecate while standing, but much of the soiling of the stall surface occurs when cows defecate while lying down (Tucker et al., 2005). Understanding why cows fail to stand before defecating is key for the design and management of lying stalls that keep cows clean. We hypothesize that this failure to stand before defecation is a learned behaviour resulting from the pain and injuries that result from standing up and lying down in poorly designed stalls, but new research is required to understand the development of this behaviour and to determine how this understanding could be used to develop housing and management that improves cow cleanliness.

In summary, docking is not motivated by the desire to harm cows but rather to keep cows clean. Increasing our understanding of the views of producers, including those in favour of docking, has helped to identify new approaches to achieving change. Specifically, we recommend extension efforts directed at producers that provide effective management strategies for keeping cows clean, in addition to showing the evidence that docking harms cows and is not helpful for improving cleanliness or udder health.

\section{Pain control for dehorning and disbudding}

It is clear that the common procedures of disbudding and dehorning cause pain (for a review, see Stafford and Mellor, 2005), but despite the ready availability of effective pain control methods many farms provide no pain mitigation for these procedures (USDA, 2009; even in Canada where the Code of Practice for the Care and Handling of Dairy Cattle requires the use of pain control, Vasseur et al., 2010).

Unlike tail docking, which simply requires producers to stop a management intervention, providing pain relief involves some extra labour and expense for supplies. These extras are sometimes viewed as barriers to change. Indeed, in our work examining views around this issue (Robbins et al., in press), those against providing pain relief sometimes cited concerns about costs for the producer and the time required for the procedure. Others opposed to providing pain relief argued that the pain experienced was minimal and short lasting, and that pain control methods had little effect.

These comments suggest at least a few different approaches for improving the implementation of pain relief. One is that extension efforts need to provide more information to farmers on the likely costs and to better contextualize these figures. Multimodal treatment (including a local block and a non-steroidal anti-inflammatory) can cost less than a cup of coffee. Moreover, providing pain relief actually reduces the growth check that otherwise occurs after dehorning (Faulkner and Weary, 2000; Baldridge et al., 2011; Coetzee et al., 2012), so even in strict financial terms the minimal cost may be a good investment. One way to contextualize the cost is to compare this expense with total costs of rearing a replacement heifer ( $\approx 2500$ USD; Gabler et al., 2000). In this context, it is easier to judge if the extra expense (if any) meaningfully affects the bottom line.

Beliefs about the duration of the pain response and the efficacy of treatment can be targeted directly by reviewing the scientific evidence from a number of sources showing the more than $24 \mathrm{~h}$ of behavioural and physiological pain responses and the efficacy of various methods of pain mitigation, including local blocks to essentially eliminate the 
intra-operative pain and non-steroidal anti-inflammatory drugs to greatly reduce post-operative pain (for review, see Stafford and Mellor, 2011).

The belief that pain is relatively minor or somehow does not really matter to the calf must also be specifically targeted. This view may correspond to our own everyday experiences in which we often experience at least some physical pain that has little effect on our quality of life. Unfortunately, very little work to date has attempted to determine how much different types of pain matter to animals. In humans, pain associated with low mood is much more likely to be detrimental to the patient's quality of life, and this thinking can also be applied to consider when pain is likely to result in suffering in animals (Weary, 2014). In recent work, we used cognitive bias testing (see Mendl et al., 2009) to determine if calves experience a low mood state (as indicated by a pessimistic response to an ambiguous visual stimulus) in the hours following hot-iron disbudding. Calves were first trained using a milk reward to discriminate between red and white colours on a video screen, and then tested with ambiguous screen colours (i.e. shades of pink) before and after disbudding. Before disbudding, the calves responded as expected, for example visiting the screen midway between red and white about half the time. However, in the $24 \mathrm{~h}$ following disbudding, calves showed a pessimistic bias, responding less frequently than expected to the ambiguous test screens (Neave et al., 2013; Daros et al., 2014). This type of evidence directly targets the beliefs of skeptics by showing that dehorning pain has a sustained effect on the calf's mood.

In summary, responses on the issue of pain relief illustrate a number of beliefs (e.g. that pain is short or relatively trivial) and perceived barriers (e.g. that effective pain control methods are expensive or unavailable). These results provide direction on how to better target extension efforts for producers, specifically focusing on the nature and duration of the pain response, providing lists of approved and efficacious drugs, providing a breakdown of costs and benefits together with context to evaluate the impact on farm profitability, and reviewing the evidence that this pain does cause calves to suffer.

\section{Pasture access}

Access to pasture is an increasingly contentious issue in countries where total confinement systems have become common. For example, $<30 \%$ of US cows have access to pasture at some time during their lactation (USDA, 2010), but when asked their views many people place considerable value on cattle having access to pasture (e.g. Boogaard et al., 2008; Ellis et al., 2009). Work using the Cow Views engagement tool described above found that almost no participants were opposed to providing pasture access, including producers and people unaffiliated with the dairy industry (Schuppli et al., 2014). However, one important theme to emerge from the qualitative analysis was the perceived lack of feasible methods for how to incorporate pasture into the management of large, modern farms.
Perceived barriers included the lack of access to land, poor grazing conditions and concern that pasture access would lead to lower levels of milk production.

Public concerns about animal agriculture are often related to restrictions of movement (Benard and de Cock Buning, 2013), suggesting that indoor housing may still be accepted if less confining. Pasture access also may be valued for different reasons by different people, for example because grazing is seen to be as natural, or because access to pasture comes with other attributes such as more space per animal and access to fresh air.

Work by our group at UBC (Legrand et al., 2009; Falk et al., 2012) has shown that cows have a strong preference for access to pasture during the night but remain indoors for the majority of the day, when temperature and humidity are high. Others have also shown that cows preferentially use indoor housing for protection from environmental conditions (Charlton et al., 2011a and 2011b) and spend more time indoors as the season progresses from summer to winter (Krohn et al., 1992) and on days when it rains (Charlton et al., 2011a). Moreover, high yielding dairy cows spend more time indoors when provided a choice between indoor cubicle housing with access to a total mixed ration (TMR) $v$. access to pasture where the TMR was also provided (Charlton et al., 2011b). Collectively, this work suggests that integrating the notion of 'choice' may be one worthy line of research to pursue when designing housing systems for dairy cattle, given that this enables the cow to decide when she wants to access the outdoors. This type of hybrid system allows for the high levels of milk production. In one study, we provided cows either exclusively indoor housing or indoor housing during the day and pasture at night. Cows allowed pasture access at night maintained the same high levels of milk production and TMR intake as the cows that were kept exclusively indoors (Chapinal et al., 2010).

We recognize that the issue of access to pasture is complex, particularly when one considers the potential impacts of housing systems on the environment (see von Keyserlingk et al., 2013). However, work to date has shown a high level of consensus on the desirability for some type of pasture access. We encourage more social science work to better understand what aspects of 'pasture' are considered most important, together with more biological and production work to design dairy systems that address the perceived constraints of producers and resonate with the broadly held public values.

\section{Early separation of cow and calf}

The calf is separated from the dam within the first hours after birth in many modern dairy operations, but this practice is the most contentious of any topic we have studied date (Ventura et al., 2013). Opposition to early separation was high among participants with no involvement in the dairy industry, while most people working within the dairy industry (including farmers) were in support of early separation, sometimes because they perceived that there were no practical alternatives. 
Weary, Ventura and von Keyserlingk

Despite this diversity in views, participants often expressed similar types of values (including key components of animal welfare like affective state and health) when justifying their position, suggesting some room for consensus. For example, those who supported early separation argued that the practice minimizes emotional distress for cow and calf and that it promotes calf health. Opponents argued that early separation reduced opportunities for cow and calf to experience positive states and that it compromised cow health. Interestingly, both perspectives have at least some scientific support. For example, research has shown that separation distress is greater if cow and calf are allowed to remain together for longer periods before they are eventually separated (Weary and Chua, 2000; Flower and Weary, 2001). On the other hand, allowing the cow and calf to remain together does appear to confer benefits for cow health (Krohn et al., 1990 and 1999) without compromising production (Metz, 1987; Flower and Weary, 2001). Thus, while the science provides an unambiguous resolution to issues like tail-docking, the science in support (or opposition) to early separation is less clear.

Clearly, there is a need for further health-based research to more fully document the health risks and benefits associated with cow-calf contact. In particular, we call for research that is not overly simplistic (e.g. focusing on just a single type of infection); evidence-based practice requires a comprehensive assessment of the various risks and benefits. We also advocate demonstration projects showing a variety of systems for allowing contact in practice and thus targeting the perceived lack of realistic methods.

In this case, as with pasture, there may also be room for the development of intermediate solutions. One reason some people oppose early separation is the high levels of calf morbidity and mortality on many farms (Ventura et al., 2013), a concern echoed by industry stakeholders in more recent focus-group-based research (Ventura et al., 2015). Thus, opposition to conventional methods of calf rearing may wane if the dairy industry is able to adopt and maintain consistently high standards of calf care. We particularly encourage the development of systems that allow calves to drink more milk, more naturally (e.g. teat-based ad libitum systems) and systems that allow for some type of social interaction (e.g. housing in pairs or small groups). More complex social environments confer important benefits for the calf, for example, decreased weaning stress, lower reactivity in novel environments, improved social behaviour and enhanced performance when compared with calves housed individually (e.g. De Paula Vieira et al., 2010 and 2012, Meagher et al., 2015).

As various alternatives are developed and tested by researchers, it is important to maintain on-going engagement with industry (to ensure that the innovations meet their perceived constraints) and the public (to ensure that these options resonate with mainstream values). We suggest thinking of the process of innovation as a cycle starting with consultation to understand stakeholder views, leading to scientific innovation, and then continued research and consultation to determine if the innovation actually meets the original concerns or creates new concerns.

\section{Looking forward}

Above we introduced just a few examples for how we engaged participants within and outside the dairy industry on contentious issues around animal welfare. Both our online and focus group studies provide a social context for these discussions. This context may introduce biases (e.g. making individuals more likely to say what they think 'should' be said; see Podsakoff et al., 2003), but people's views about contentious issues rarely exist in a vacuum. We believe it is important to explore the interpretations they bring to these issues while they are in a social context. An advantage of our online approach was that it allowed user anonymity and created a safe-space in which individuals could discuss difficult issues with less fear of social judgment; many consultation efforts utilize online techniques as a means of improving engagement (Rowe and Gammack, 2004). Diverse methodologies are available for public engagement (e.g. Swanson et al., 2011); as more social science research takes place on animal welfare issues we encourage the adoption of a range of methodologies that should help understand the root of conflicts around farming practices.

It is often argued that people's criticisms of practices in agriculture might sometimes be based upon a poor understanding of the real conditions on farms (Heleski et al., 2006; Hubbard et al., 2007; Spooner et al., 2012; Benard and de Cock Buning, 2013). According to this 'informational deficit model' (Wynne and Irwin, 1996; Einsiedel, 2000), if lay stakeholders were better educated about practices on farms some of their criticisms might evaporate. Although knowledge is not the sole determinant in people's attitudes towards a particular issue, it does contribute to people's frame of reference (see Te Velde et al., 2002) and we agree that engagement via the provision of some information is critical in our ability to deliberate on complex issues (Castle and Culver, 2006). In the studies described above we provided some context for the participants, but this was limited. In some other work we have provided much greater access to information (e.g. Schuppli et al., 2015). Other research has gone further, in some cases taking lay participants onto working farms (Boogaard et al., 2008 and 2011; Krystallis et al., 2009) and gauging their responses in context. We encourage more work on the role of information and how it can be best provided to help inform debate.

We also see the need for work to address the polarization of views and lack of inter-stakeholder dialogue on farm animal welfare. The social aspect of the Cow Views site was intentionally created to bring diverse stakeholders into contact with the views of others, but we have not formally tested the effect of this and other forms of interaction on stakeholder views. Other research has shown the value of engaging multiple stakeholders in the process of designing improved housing for farm animals. For example, Groot Koerkamp and Bos (2008) showed how multi-stakeholder 
engagement can help in the development of more socially sustainable housing and management systems for laying hens.

One promising approach for new research is frame reflection, as described by Benard and de Cock Buning (2013). In this study, both citizens and farmers were organized into focus groups and asked to temporarily shift their frames of reference to consider the other group's perspective. The results indicated that farmers were less able or willing to shift their frame of reference, but citizens were able to do so and this seemed to help in the development of a more differentiated and inclusive concept of animal welfare. Such methods have the potential to develop a 'shared vision' for the future of animal care, in part by helping to address certain barriers like the inability of some people within one sector to acknowledge the legitimacy of others' views.

\section{Acknowledgements}

The authors thank Peter Danielson and the Norms Evolving in Response to Dilemmas group at the University of British Columbia (UBC) for support in developing the Cow Views platform. They are also grateful to Cathy Schuppli, Jesse Robbins and others at UBC for the contributions to the ideas and the data described in the examples we review.

\section{References}

Aerts S 2013. The consumer does not exist: overcoming the citizen/consumer paradox by shifting focus. In The ethics of consumption: the citizen, the market and the law (ed. H Rocklinsberg and P Sandin), pp. 172-175. 11th Cong Eur Soc Agric Food Ethics (Eursafe), Uppsala, Sweden.

Ajzen I 2001. Nature and operation of attitudes. Annual Review of Psychology $52,27-58$

Ajzen I and Fishbein M 1980. Understanding attitudes and predicting social behavior. Prentice-Hall, Englewood-Cliggs, NJ, USA.

Ajzen I and Madden TJ 1986. Prediction of goal-directed behavior: attitudes, intentions, and perceived behavioral control. Journal of Experimental Social Psychology 22, 453-474.

Baldridge SL, Coetzee JF, Dritz SS, Reinbold JB, Gehring R, Havel J and Kukanich B 2011. Pharmacokinetics and physiologic effects of intramuscularly administered xylazine hydrochloride-ketamine hydrochloride-butorphanol tartrate alone or in combination with orally administered sodium salicylate on biomarkers of pain in Holstein calves following castration and dehorning. American Journal of Veterinary Research 72, 1305-1317.

Barnett JL, Coleman GJ, Hemsworth PH, Newman EA, Fewings-Hall S and Ziini C 1999. Tail docking and beliefs about the practice in the Victorian dairy industry. Australian Veterinary Journal 77, 742-747.

Bell NJ, Bell MJ, Knowles TG, Whay HR, Main DJ and Webster AJF 2009. The development, implementation and testing of a lameness control programme based on HACCP principles and designed for heifers on dairy farms. The Veterinary Journal 180, 178-188.

Bem DJ 1970. Beliefs, attitudes and human affairs. Brooks/Cole Publishing Company, Monterey, CA, USA.

Benard M and de Cock Buning T 2013. Exploring the potential of Dutch pig farmers and urban-citizens to learn through frame reflection. Journal of Agricultural and Environmental Ethics 26, 1015-1036.

Bernardi F, Fregonesi J, Winckler C, Veira DM, von Keyserlingk MAG and Weary DM 2009. The stall design paradox: neck rails increase lameness but improve udder and stall hygiene. Journal of Dairy Science 92, 3074-3080.

Boogaard K, Oosting J and Bock B 2008. Defining sustainability as a sociocultural concept: citizen panels visiting dairy farms in the Netherlands. Livestock Science 117, 24-33.
Boogaard K, Boekhorst JS, Oosting J and Sørensen T 2011. Socio-cultural sustainability of pig production: citizen perceptions in the Netherlands and Denmark. Livestock Science 140, 189-200.

Borgen SO and Skarstad GA 2007. Norwegian pig farmers' motivations for improving animal welfare. British Food Journal 109, 891-905.

Brannen J 2005. Mixing methods: the entry of qualitative and quantitative approaches into the research process. International Journal of Social Research Methodology 8, 173-184.

Casler K, Bickel L and Hackett E 2013. Computers in human behavior separate but equal? A comparison of participants and data gathered via Amazon's MTurk, social media, and face-to-face behavioral testing. Computers and Human Behavior 29, 2156-2160.

Castle D and Culver K 2006. Public engagement, public consultation, innovation and the market. Integrated Assessment Journal 6, 137-152.

Chapinal N, Goldhawk C, de Passillé AM, von Keyserlingk MAG, Weary DM and Rushen J 2010. Overnight access to pasture does not reduce milk production or feed intake in dairy cows. Livestock Science 129, 104-110.

Charlton GL, Rutter SM, East M and Sinclair LA 2011a. Preference of dairy cows: indoor cubicle housing with access to a total mixed ration vs. access to pasture. Applied Animal Behaviour Science 130, 1-9.

Charlton GL, Rutter SM, East M and Sinclair LA 2011b. Effects of providing total mixed rations indoors and on pasture on the behavior of lactating dairy cattle and their preference to be indoors or on pasture. Journal of Dairy Science 94, 3875-3884.

Coetzee JF, Mosher RA, KuKanich B, Gehring R, Robert B, Reinbold JB and White BJ 2012. Pharmacokinetics and effect of intraveneous meloxicam in weaned Holstein calves following scoop dehorning without local anesthesia. BMC Veterinary Research 8, 153.

Cross RM 2005. Exploring attitudes: the case for Q methodology. Health Education Research 20, 206-213.

Danielson P 2010. Designing a machine to learn about the ethics of robotics: the N-reasons platform. Ethics and Information Technology 12, 251-261.

Daros RR, Costa JHC, von Keyserlingk MAG, Hötzel MJ and Weary DM 2014. Separation from the dam causes negative judgment bias in dairy calves. PLoS One 9, e98429.

De Paula Vieira A, von Keyserlingk MAG and Weary DM 2010. Effects of pair versus single housing on performance and behavior of dairy calves before and after weaning from milk. Journal of Dairy Science 93, 3079-3085.

De Paula Vieira A, von Keyserlingk MAG and Weary DM 2012. Presence of an older weaned companion influences feeding behavior and improves performance of dairy calves before and after weaning from milk. Journal of Dairy Science 95, 3218-3224.

DeVries TJ, Vankova M, Veira DM and von Keyserlingk MAG 2007. Short communication: usage of mechanical brushes by lactating dairy cows. Journal of Dairy Science 90, 2241-2245.

Driessen C 2012. Farmers engaged in deliberative practices: an ethnographic exploration of the mosaic of concerns in livestock agriculture. Journal of Agricultural and Environmental Ethics 25, 163-179.

Eicher SD, Morrow-Tesch JL, Albright JL and Williams RE 2001. Tail-docking alters fly numbers, fly-avoidance behaviors, and cleanliness, but not physiological measures. Journal of Dairy Science 84, 1822-1828.

Einsiedel EF 2000. Understanding 'publics' in the public understanding of science. In Between understanding and trust: the public, science and technology (ed. M Dierkes and CV Grote), pp. 205-216. Harwood Academic Publishers, Amsterdam, The Netherlands.

Ellis KA, Billington K, McNeil B and McKeegan DEF 2009. Public opinion on UK milk marketing and dairy cow welfare. Animal Welfare 18, 267-282.

Falk AC, Weary DM, Winckler C and von Keyserlingk MAG 2012. Preference for pasture versus freestall housing by dairy cattle when stall availability indoors is reduced. Journal of Dairy Science 95, 6409-6415.

Faulkner PM and Weary DM 2000. Reducing pain after dehorning in dairy calves. Journal of Dairy Science 83, 2037-2041.

Feola G and Binder CR 2010. Towards an improved understanding of farmers' behaviour: the integrative agent-centred (IAC) framework. Ecological Economics 69, 2323-2333.

Fishbein M and Ajzen I 1975. Belief, attitude, intention, and behaviour: an introduction to theory and research. Addison-Wesley, Reading, MA, USA. 
Flower FC and Weary DM 2001. Effects of early separation on the dairy cow and calf. II: separation at 1 day and 2 weeks after birth. Applied Animal Behaviour Science 70, 275-284.

Fraser D 2008. Understanding animal welfare: the science in its cultural context. Wiley-Blackwell, Oxford, UK.

Fulwider WK, Grandin T, Rollin BE, Engle TE, Dalsted NL and Lamm WD 2008. Survey of dairy management practices on one hundred thirteen North Central and Northeastern United States dairies. Journal of Dairy Science 91, 1686-1692.

Gabler M, Tozer PR and Heinrichs AJ 2000. Development of a cost analysis spreadsheet for calculating the costs to raise a replacement dairy heifer. Journal of Dairy Science 83, 1104-1109.

Groot Koerkamp PWG and Bos AP 2008. Designing complex and sustainable agricultural production systems: an integrated and reflexive approach for the case of table egg production in the Netherlands. NJAS - Wageningen Journal of Life Sciences 55, 113-138.

Hansen J, Holm L, Frewer L, Robinson P and Sandøe P 2003. Beyond the knowledge deficit: recent research into lay and expert attitudes to food risks. Appetite 41, 111-121.

Hansson J and Lagerkvist C 2014. Defining and measuring farmers' attitudes to farm animal welfare. Animal Welfare 23, 47-56.

Heleski C and Zanella A 2006. Animal science student attitudes to farm animal welfare. Anthrozoos 19, 3-16.

Heleski C, Mertig A and Zanella A 2004. Assessing attitudes toward farm animal welfare: a national survey of animal science faculty members. Journal of Animal Science 82, 2806-2814.

Heleski C, Mertig A and Zanella A 2005. Results of a national survey of US veterinary college faculty regarding attitudes toward farm animal welfare. Journal of the American Veterinary Medical Association 226, 1538-1546.

Heleski C, Mertig A and Zanella A 2006. Stakeholder attitudes toward farm animal welfare. Anthrozoos 19, 290-307.

Hubbard C, Bourlakis M and Garrod G 2007. Pig in the middle: farmers and the delivery of farm animal welfare standards. British Food Journal 109, 919-930.

Ingenbleek PTM and Immink VM 2011. Consumer decision making for animalfriendly products: synthesis and implications. Animal Welfare 20,11-19.

Kauppinen T, Vainio A, Valros A, Rita H and Vesala K 2010. Improving animal welfare: qualitative and quantitative methodology in the study of farmers attitudes. Animal Welfare 19, 523-536.

Krohn CC, Foldager J and Mogensen L 1999. Long-term effect of colostrum feeding methods on behaviour in female dairy calves. Acta Agriculturae Scandinavica, Section A - Animal Science 49, 57-64.

Krohn CC, Jonasen B and Munksgaard L 1990. Cow-calf relations. 2: The effect of 0 vs. 5 days suckling on behaviour, milk production and udder health of cows in different stabling. Report No. 678. National Institute of Animal Science, Foulum, Denmark.

Krohn CC, Munksgaard L and Jonasen B 1992. Behaviour of dairy cows kept in extensive (loose housing/pasture) or intensive (tie stall) environments-I. Experimental procedure, facilities, time budgets- diurnal and seasonal conditions. Applied Animal Behaviour Science 34, 37-47.

Krystallis A, de Barcellos MD, Kügler JO, Verbeke W and Grunert KG 2009 Attitudes of European citizens towards pig production systems. Livestock Science 126, 46-56.

Lay DC, Fulton RM Jr, Hester PY, Karcher DM, Kjaer JB, Mench JA, Mullens BA, Newberry RC, Nicol CJ, O'Sullivan NP and Porter R 2011. Hen welfare in different housing systems. Poultry Science 90, 278-294.

Legrand AL, von Keyserlingk MAG and Weary DM 2009. Preference and usage of pasture versus freestall housing by lactating dairy cattle. Journal of Dairy Science 92, 3651-3658.

Lerner $\mathrm{H}$ and Algers B 2013. Tail docking in the EU: a case of routine violation of an EU Directive. Proceedings of the 11th Congress of the European Society for Agricultural and Food Ethics. Uppsala, Sweden. pp. 374-378.

Levine ED, Mills DS and Houpt KA 2005. Attitudes of veterinary students at one US college toward factors relating to farm animal welfare. Journal of Veterinary Medical Education 32, 481-490.

Lombard JE, Tucker CB, von Keyserlingk MAG, Kopral CA and Weary DM 2010. Associations between cow hygiene, hock injuries, and free stall usage on US dairy farms. Journal of Dairy Science 93, 4668-4676.

Mackintosh CG, Schollum LM, Blackmore DK and Marshall RB 1982. Epidemiology of leptospirosis in dairy farm workers in Manawatu. Part II.
A case-control study of high and low risk farms. New Zealand Veterinary Journal 30, 73-76.

Meagher RK, Daros RR, Costa JHC, von Keyserlingk MAG, Hötzel M and Weary DM 2015. Effects of degree and timing of social housing on reversal learning and response to novel objects in dairy calves. PLOS ONE (in press).

Mench JA, Sumner DA and Rosen-Molina JT 2011. Sustainability of egg production in the United States - the policy and market context. Poultry Science 90, 229-240.

Mendl M, Burman OHP, Parker RMA and Paul ES 2009. Cognitive bias as an indicator of animal emotion and welfare: emerging evidence and underlying mechanisms. Applied Animal Behaviour Science 111, 161-181.

Metz J 1987. Productivity aspects of keeping dairy cow and calf together in the post-partum period. Livestock Production Science 16, 385-394.

National Farm Animal Care Council 2009. Code of practice for the care and handling of dairy cattle. National Farm Animal Care Council, Ottawa, Ontario, Canada.

Neave HW, Daros RR, Costa JHC, von Keyserlingk MAG and Weary DM 2013. Pain and pessimism: dairy calves exhibit negative judgment bias following hotiron disbudding. PLoS One 8, e80556.

Pivetti M 2007. Natural and unnatural: activists' representations of animal biotechnology. New Genetics and Society 26, 137-157.

Podsakoff PM, Mackenzie SB and Lee J-Y 2003. Common method biases in behavioral research: a critical review of the literature and recommended remedies. Journal of Applied Psychology 88, 879-903.

Prickett RW, Norwood FB and Lusk JL 2010. Consumer preference for farm animal welfare: results from a telephone survey of US households. Anima Welfare 19, 335-347.

Robbins JA, Weary DM, Schuppli CA and von Keyserlingk MAG (in press). Stakeholder views on treating pain due to dehorning dairy calves. Animal Welfare.

Rowe G and Gammack JG 2004. Promise and perils of electronic public engagement. Science and Public Policy 31, 39-54.

Schreiner DA and Ruegg PL 2002. Effects of tail docking on milk quality and cow cleanliness. Journal of Dairy Science 85, 2503-2511.

Schuppli CA, von Keyserlingk MAG and Weary DM 2014. Access to pasture for dairy cows: responses from an on-line engagement. Journal of Animal Science 92, 5185-5192.

Schuppli CA, Molento C and Weary DM 2015. Understanding attitudes towards the use of animals in research using an online public engagement tool. Public Understanding of Science 24, 358-374.

Seligman C, Olson JM and Zanna MP (ed.) 1996. The psychology of values: the Ontario symposium, vol. 8. Erlbaum, Mahwah, NJ, USA.

Spooner JM, Schuppli CA and Fraser D 2012. Attitudes of Canadian beef producers toward animal welfare. Animal Welfare 21, 273-283.

Stafford KJ and Mellor DJ 2005. Dehorning and disbudding distress and its alleviation in calves. The Veterinary Journal 169, 337-349.

Stafford KJ and Mellor DJ 2011. Addressing the pain associated with disbudding and dehorning in cattle. Applied Animal Behaviour Science 135, 226-231.

Swanson JC, Lee $Y$, Thompson PB, Bawden R and Mench JA 2011. Integration: valuing stakeholder input in setting priorities for socially sustainable egg production. Poultry Science 90, 2110-2121.

Te Velde $\mathrm{H}$, Aarts $\mathrm{N}$ and van Workum C 2002. Dealing with ambivalence: farmers' and consumers' perceptions of animal welfare in livestock breeding. Journal of Agricultural and Environmental Ethics 15, $203-219$.

Tucker CB, Fraser D and Weary DM 2001. Tail docking dairy cattle: effects on cow cleanliness and udder health. Journal of Dairy Science 84, 84-87.

Tucker CB, Weary DM and Fraser D 2005. Influence of neck-rail placement on free-stall preference, use and cleanliness. Journal of Dairy Science 88, 2730-2737. USDA 2009. Dairy 2007: Changes in dairy cattle health and management practices in the United States, 1996-2007. USDA:APHIS:VS, CEAH. Fort Collins, CO.

USDA 2010. Dairy 2007: Facility characteristics and cow comfort on U.S. dairy operations, 2007. USDA:APHIS:VS, CEAH. Fort Collins, CO.

Vanhonacker F, Van Poucke E, Tuyttens F and Verbeke W 2010. Citizens' views on farm animal welfare and related information provision: Exploratory insights from Flanders, Belgium. Journal of Agricultural and Environmental Ethics 23, 551-569. 
Vanhonacker F, Verbeke W, Van Poucke E and Tuyttens FA 2008. Do citizens and farmers interpret the concept of farm animal welfare differently? Livestock Science 116, 126-136.

Vasseur E, Borderas F, Cue RL, Lefebvre D, Pellerin D, Rushen J, Wade KM and de Passile AM 2010. A survey of dairy calf management practices in Canada that affect animal welfare. Journal of Dairy Science 93, 1307-1315.

Ventura B, von Keyserlingk MAG and Weary DM 2015. Animal welfare concerns and values of stakeholders within the dairy industry. Journal of Agricultural and Environmental Ethics 28, 109-126.

Ventura B, Schuppli C, von Keyserlingk MAG and Weary DM 2013. Views on contentious practices in dairy farming: the case of early cow-calf separation. Journal of Dairy Science 96, 6105-6116.

von Keyserlingk MAG, Martin NP, Kebreab E, Knowlton KF, Grant RJ, Stephenson M, Sniffen CJ, Harner JP, Wright AD and Smith SI 2013. Invited review: sustainability of the US dairy industry. Journal of Dairy Science $96,5405-5425$.
Warren $C A B$ and Karner TX 2010. Discovering qualitative methods: field research, interviews, and analysis, 2nd edition. Oxford University Press, New York, NY, USA.

Weary DM 2014. What is suffering in animals?. In Dilemmas in animal welfare (ed. MC Appleby, DM Weary and P Sandøe), pp. 188-202. CAB International, Wallingford, UK.

Weary DM and Chua B 2000. Effects of early separation on the dairy cow and calf. 1: Separation at $6 \mathrm{~h}, 1$ day and 4 days after birth. Applied Animal Behaviour Science 69, 177-188.

Weary DM, Schuppli CA and von Keyserlingk MAG 2011. Tail docking dairy cattle: responses from an online engagement. Journal of Animal Science 89, 3831-3837.

Wynne B and Irwin A 1996. Misunderstanding science? The public reconstruction of science and technology. Cambridge University Press, Cambridge, UK. 